\title{
Evaluation of Packaging Form Regarding Consumers' Sentimental Response to Bottled Beverage Containers
}

\author{
Hua-Cheng Chang ${ }^{1}$, Kuo-Li Huang ${ }^{2}$, Hung-Yuan Chen ${ }^{2, *}$ and Chen-I Huang ${ }^{2}$ \\ 1 Department of Multimedia and Entertainment Science, Southern Taiwan University of Science and \\ Technology, No. 1, Nantai Street, Yongkang District, Tainan City 71005, Taiwan; hcchang@stust.edu.tw \\ 2 Department of Visual Communication Design, Southern Taiwan University of Science and Technology, \\ No. 1, Nantai Street, Yongkang District, Tainan City 71005, Taiwan; z3z@stust.edu.tw (K.-L.H.); \\ zay@stust.edu.tw (C.-I.H.) \\ * Correspondence: hungyuan@stust.edu.tw; Tel./Fax: +886-6-253-3131 (ext. 8202)
}

Received: 8 April 2018; Accepted: 28 May 2018; Published: 29 May 2018

\begin{abstract}
With the rise of consumer awareness in the increasingly competitive marketplace, attracting consumers' attention to a successful product is an important issue. Regarding consumers' purchasing decisions for bottled beverages, decision-making is driven not only by a beverage's flavor attributes or brand impression, but also by the visual effect of its packaging design. Accordingly, how to create an attractive beverage packaging based on consumers' affective requirements has become one of the most important concerns to promote sales of beverages. Many studies have discussed the visual design of container form design based on consumers' sentimental responses by means of investigation and analysis. However, most research has focused on the exploration of a single beverage category, and rarely on the discussion of various beverage categories in terms of container design. To explore the issue, three beverage categories of PET (Polyethylene terephthalate) container form samples are chosen as examples of carbonated drinks, water drinks, and tea drinks. A series of visual evaluations of the PET container form was conducted to explore how the features influence consumers' sentimental responses, and to compare the difference between the container features for the three categories of bottled beverages. The research results can provide bottled beverage designers/manufacturers with some meaningful suggestions for developing a new container design that meets consumers' sentimental expectations.
\end{abstract}

Keywords: bottled beverage container; packaging design; form design; consumers' sentimental response; visual evaluation

\section{Introduction}

With the rise of consumer awareness in the increasingly competitive marketplace, attracting consumers' attention to a successful beverage product is an important issue. When consumers purchase a beverage product, they tend to go with their personal feelings, psychological perceptions, and sentimental responses [1,2]. Thus, beverage manufacturers should consider not only the ingredients of the beverage product (e.g., beverage flavor or taste attributes), but also the visual development of the product's packaging since the packaging relates to the consumers' attention, emotional needs, sentimental responses, and psychological perceptions. To explore consumers' sentimental response (CSR) to beverage product packaging, many researchers have evaluated the relationship between CSR and the factors of beverage packaging. For instance, Giese et al. (2014) argued that the labeling of product packaging could evoke CSR and have a significant influence on product acceptance [3]. Ares and Deliza (2010) and Becker et al. (2011) indicated that the color of packaging could play an important role by creating strong associations [1,4]. Apart from the labeling and color of product 
packaging, Becker et al. (2011) and Luo et al. (2012) argued that the design of a beverage bottle may attract consumers, endow beverage products with more sentimental qualities, and increase the brand identification [1,2]. Cases have shown that the bottle form of a beverage product (e.g., Coca Cola and Evian mineral water) can attract consumers in the marketplace. Therefore, a well-done container form design gives a bottled beverage product a powerful advantage by evoking CSR and attracting attention.

Many systematic approaches have been proposed for modeling the correlation between packaging form features and the CSR [2,4-6]. Among such approaches, Kansei Engineering (KE) has set up a fundamentally consumer-oriented and systematic approach in which consumers' feelings or sentimental responses (known as "Kansei" in Japanese) are expressed using suitable image descriptions. In addition to the application of product design [7], KE has also been successfully applied to the realization of a variety of real-world commercial product packages, e.g., dairy-based dessert packaging [4], moisturizer packaging [5], beverage bottle design [2], perfume bottle packaging [8], and so forth. In terms of bottled beverage packaging, the effective application of the KE approach is determined by the definition of the container form features used to describe the packaging details and the choice of method used to analyze the correlation between the container form features and the CSR. In generally, the container features of a bottled beverage packaging are essentially the tangible physical attributes that are immediately apparent to the consumer. Intuitively, for every bottled beverage product, there exists a set of form features that dominate CSR. However, it is impossible to include every conceivable form of bottled beverage packaging within the scope of the current study. In order to examine whether these form features vary in the different beverage categories, this study has chosen specific examples of bottled packaging for three beverage categories (i.e., carbonated drinks, water drinks, and tea drinks, the three top-selling types of beverages) for illustration purposes. Therefore, it is desirable that the particular form features for these three categories of bottled beverages be identified during the early stages of the design process so that designers or manufacturers can focus their efforts on these particular design details so as to enhance the CSR of the bottled packaging.

In regard to choosing a suitable analytical technique, techniques such as Quantitative Theory Type I (QTT1) [9], Conjoint Analysis [10], and multiple linear regression [11] are commonly employed to interpret relationships between the independent and dependent variables. QTT1 is particularly useful since it is simple and transparent, and has good approximation when modeling the correlation between independent and dependent variables. It seems reasonable to suppose that the QTT1 analytical technique represents a suitable solution to explore the relationship between the container features of bottled packaging and the likely CSR in the present study. The remainder of the present study is organized as follows: Section 2 reviews the relevant literature comprising the visual design of product packaging, a morphological analysis, and the measurement of CSRs to the products or the packaging. Section 3 describes the research procedure and method. Section 4 presents the visual evaluation of bottled beverage packaging. Section 5 interprets the results and analyses of bottled beverage packaging evaluation. Section 6 offers some brief conclusions.

\section{Review of Relevant Literature}

This section reviews the major studies presented in the literature relating to the following three issues: (1) importance of product packaging form design; (2) Kansei Engineering (KE) and morphological analysis; (3) measurement of consumers' sentimental responses.

\subsection{Importance of Product Packaging Form Design}

Product packaging plays the role of a silent salesman in enhancing the initial impression of a product in the eyes of its potential consumers and increasing their purchasing desire [12]. Consumers' satisfaction with a product is dependent to a large extent on the manner in which a product or its packaging is designed. Moreover, a product packaging design can be regarded as a collection of individual features related in some specific manner. The packaging features are essentially the tangible 
physical attributes that are immediately apparent to the consumer. In this sense, for every consumer product, there exists a set of features that dominates the CSR. Silayoi and Speece (2007) note that how consumers perceive the subjective entity of a product through the packaging is crucial for determining its commercial success [13]. Many researchers argue that the greater visibility of packaging helps a product attract the target consumers' attention and arouses purchase desire by means of its visual elements $[3,4,14]$. For example, labeling (graphic design), color, material, and form are the major elements of typical packaging and play an important role in attracting consumers' attention, raising their satisfaction, and enhancing the quality of consumers' responses to a product [15-18]. In addition, the published literature contains many discussions regarding the development of bottled products' package design based on consumers' psychological responses $[5,6,19,20]$. Furthermore, Becker et al. (2011) indicated that the design of product packaging may attract the consumer when purchasing products [1]. Moreover, Luo et al. (2012) argued that conspicuous and distinctive form design for bottled product packaging could attract consumers' attention and increase brand identification [2]. Cases have shown that the bottle design of Coca Cola and Absolut Vodka can still be identified in the marketplace even when label design and color design are lacking. Based on the abovementioned review, this indicates that packaging form not only serves to protect the product's integrity, form, and features, but also provides a powerful vehicle for imparting relevant messages and product imagery directly to the target consumers.

\subsection{Kansei Engineering (KE) and Morphological Analysis}

Kansei Engineering (KE) is a consumer-centered design approach aimed at translating consumers' feelings, affective responses, or product images (known as "Kansei" in Japanese) into concrete design elements. According to Nagamachi [7], KE addresses four main issues, namely: (1) how to grasp consumers' feeling about a product in terms of ergonomic and psychological estimation, (2) how to identify the design characteristics of the product based on consumers' feelings, (3) how to build $\mathrm{KE}$ as an ergonomic technology, and (4) how to adjust the product design to fit current societal change or emerging consumer preferences. KE has emerged as one of the most powerful techniques for taking account of the correlation between the product elements and the induced product or packaging image [21]. As a result, it has attracted significant attention in the literature on products and packaging $[2,4,5,8,11,21]$.

With respect to the product features, KE approaches commonly rely on morphological analysis concepts such as "elements/items" and "features/categories" based on pictorial profiles with accompanying text descriptions to generate high-level descriptions of the design variables that collectively define the overall product form. Morphological analysis was introduced by Zwicky (1969), an astronomer who successfully used this method and a pioneer of the construction of reaction engines [22]. The morphological analysis is actually a group of solutions that share the same structure. This method decomposes a system, product, or process into its essential sub-concepts, with each concept representing a dimension in a multi-dimensional matrix. Morphological analysis has several advantages over less structured approaches. First, it may help designers to discover new relationships or configurations and allow designers to find possible solutions to complex problems characterized by several attributes (parameters). Second, it encourages the identification and investigation of boundary conditions, i.e., the limits and extremes of different contexts and factors. Third, it can provide a multitude of permutations and a systematic analysis for product designers [23]. Recently, morphological analysis has been widely applied by a number of researchers in various fields including robotics systems development [24], product design [11,25], and packaging design [2,21]. In the field of product design, morphological analysis is usually used to describe the details of a product based on human recognition of the distinctive component features, and generally relies on the concept of qualitative "elements/items" and "features/categories" (see Figure 1) that use the pictorial profiles with the text descriptions to describe the product's features. Further, in this study, it is also applied to define the beverage packaging form using the qualitative taxonomy of form features and integrated 
with Quantification Theory Type 1 analysis technique so as to develop new packaging forms by recombining the form features of existing bottled beverage packaging.

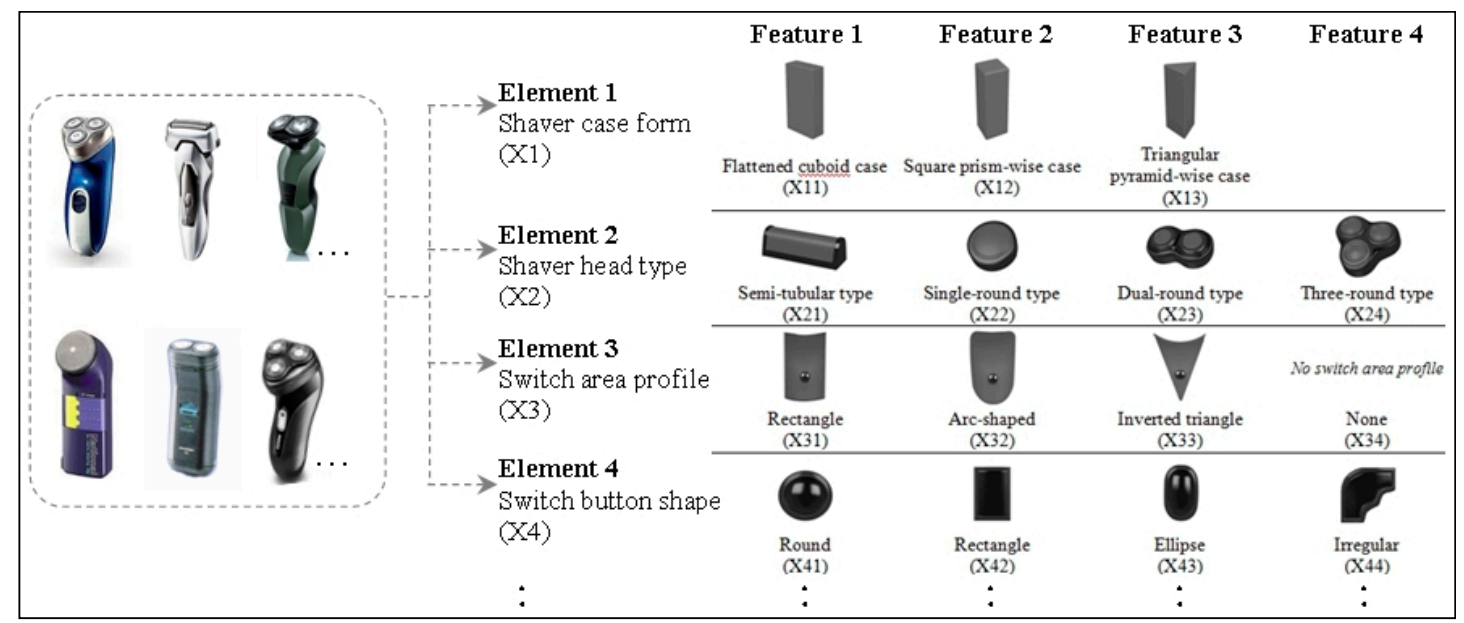

Figure 1. Conceptual illustration of "elements/items" and "features/categories" with the example of electric shavers.

\subsection{Measurement of Consumers' Sentimental Response}

With respect to evaluating CSR to product or packaging, studies have proposed a variety of techniques for discussing the perceptional meanings of a particular product or packaging form $[2,11,21]$. For example, Chang et al. (2007) developed an instrument for measuring consumers' psychological perceptions of passenger car forms, utilizing seven-point Likert scales with anchors ranging from "strongly disagree" to "strongly agree" [26,27], while Luo et al. (2012) utilized the Semantic Differential Method (SDM) presented by Osgood et al. (1957), consisting of two opposing adjectives or concepts separated by a scale, to evaluate consumers' responses to product packaging $[2,28]$. Several academic researchers used seven-point Likert scales to measure consumers' responses to the visual design of product packaging $[4,29]$. Similarly, SDM has been successfully applied to the design of moisturizer packaging [5], beverage bottle forms [2], and perfume bottle forms [30]. Apart from the abovementioned approaches, McDonagh et al. (2005) utilized a focus group approach, based on product personality profiling (PPP), mood boards, and visual product evaluation methods, to elicit consumers' responses to the appearance of a product [31].

In addition, Chen et al. (2016) presented a sorting card-based evaluation method (SCEM) for investigating the product image of an automobile profile. In the proposed method, each subject was asked to evaluate each sample in terms of each target image word by dividing the automobile profile samples (cards) into three groups, namely low $(\mathrm{L})$, medium $(\mathrm{M})$, and high $(\mathrm{H})$, in accordance with the subject's instinctive feeling regarding the degree to which the target image word accurately describe the instinctive perceptions induced by the sample [32]. Each of the three groups was then divided into three further sub-groups such that the samples were divided into a total of nine groups. Each sample group was then allocated a score from 1 to 9 (LL to HH) depending on the group to which it was assigned. Overall, these approaches are advantageous in evaluating the likely CSR to the visual design of product packaging while still in its conceptual design stage.

\section{Research Procedure and Method}

\subsection{Bottled Beverage Container Samples}

To explore a consumer's likely response to a bottled beverage container form, we started by collecting a large number of bottled beverage containers with a capacity of 450-650 mL. A total of 81 bottled beverage containers, comprising 31 mineral water (MW) bottles, 22 carbonated drink (CD) 
bottles, and 28 tea drink (TD) bottles, was collected, and these container forms are converted into gray picture samples by taking a front-view photograph. These picture samples were uniformly reduced and individually displayed on an A5-sized card. Figure 2 illustrates the total set of 81 bottled beverage container samples.

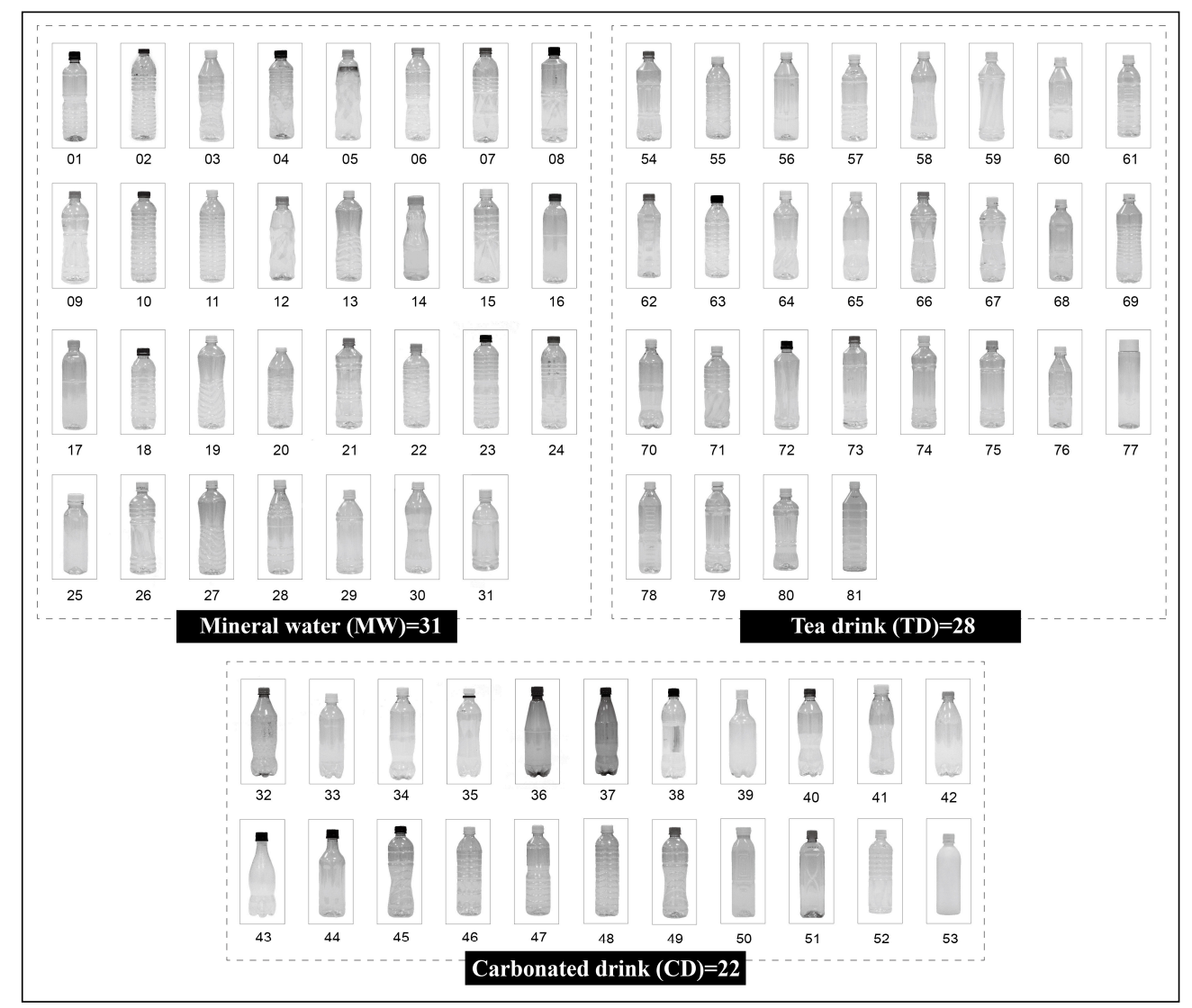

Figure 2. Eighty-one sample bottled beverage containers.

To examine the suitability of bottled beverage container forms belonging to the corresponding categories based on the judgment of consumers' cognition, a classification of container forms for bottled beverage categories was conducted. Twenty-six subjects were asked to classify the 81 sample cards into the three categories based on their visual cognition. The result of the classification investigation was calculated using Equation (1):

$$
S_{\mathrm{r}(\%)}=\frac{F_{\mathrm{SC}}}{T F_{\mathrm{sc}}}
$$

where $S_{\mathrm{r}}$ is defined as the suitability ratio (\%) between the sample and a specific category. $F_{\mathrm{sc}}$ is defined as the frequency of classification of a sample into each beverage category and $T F_{\mathrm{sc}}$ is the total frequency of classification of the sample made by a subject. Based on the calculation of classification investigation, $S_{\mathrm{r}}$ indicates the suitability regarding the correlation between the sample and a particular category.

Table 1 shows the suitability ratio (\%) of each sample, classified into the three categories (mineral water (MW), carbonated drinks (CD), and tea drinks (TD)), and the original category of each sample. From the results of the classification calculation, the samples that are different between the suitability category and the original category are eliminated since the highest percentage scores of suitability ratio of the samples do not correspond to the original category. Consequently, eight MW samples, six CD samples, and nine TD samples are eliminated from the corresponding categories samples, respectively. As shown in Figure 3, a total of 58 samples were retained for evaluation of bottled beverage packaging. 
Table 1. The suitability ratio of each sample on three beverage categories (partial).

\begin{tabular}{|c|c|c|c|c|c|c|}
\hline \multirow{2}{*}{ No. } & \multicolumn{3}{|c|}{ Suitability Ratio (\%) } & \multirow{2}{*}{$\begin{array}{l}\text { Original } \\
\text { Category }\end{array}$} & \multirow{2}{*}{$\begin{array}{c}\text { Suitability } \\
\text { Category }\end{array}$} & \multirow{2}{*}{ Decision } \\
\hline & MW & CD & TD & & & \\
\hline MW1 & $65.4 \%$ & $11.5 \%$ & $23.1 \%$ & MW & MW & \\
\hline MW2 & $69.2 \%$ & $15.4 \%$ & $15.4 \%$ & MW & MW & \\
\hline MW3 & $30.8 \%$ & $26.9 \%$ & $42.3 \%$ & MW & $\mathrm{TD}$ & Eliminated \\
\hline MW4 & $34.6 \%$ & $42.3 \%$ & $23.1 \%$ & MW & CD & Eliminated \\
\hline$:$ & : & : & : & $:$ & & : \\
\hline MW30 & $26.9 \%$ & $34.6 \%$ & $38.5 \%$ & MW & $\mathrm{TD}$ & Eliminated \\
\hline MW31 & $53.8 \%$ & $7.7 \%$ & $38.5 \%$ & MW & MW & \\
\hline CD32 & $38.5 \%$ & $53.8 \%$ & $7.7 \%$ & $\mathrm{CD}$ & $\mathrm{CD}$ & \\
\hline CD33 & $34.6 \%$ & $38.5 \%$ & $26.9 \%$ & $\mathrm{CD}$ & $\mathrm{CD}$ & \\
\hline CD34 & $38.5 \%$ & $42.3 \%$ & $19.2 \%$ & $\mathrm{CD}$ & $\mathrm{CD}$ & \\
\hline CD35 & $53.8 \%$ & $26.9 \%$ & $19.2 \%$ & $\mathrm{CD}$ & MW & Eliminated \\
\hline : & : & : & : & : & & : \\
\hline CD53 & $38.5 \%$ & $46.2 \%$ & $15.4 \%$ & $C D$ & $C D$ & \\
\hline TD54 & $38.5 \%$ & $23.1 \%$ & $42.3 \%$ & TD & TD & \\
\hline TD55 & $26.9 \%$ & $42.3 \%$ & $30.8 \%$ & TD & $C D$ & Eliminated \\
\hline TD56 & $38.5 \%$ & $11.5 \%$ & $50.0 \%$ & TD & TD & \\
\hline : & : & : & : & $:$ & & $:$ \\
\hline TD81 & $53.8 \%$ & $3.8 \%$ & $42.3 \%$ & TD & MW & Eliminated \\
\hline
\end{tabular}

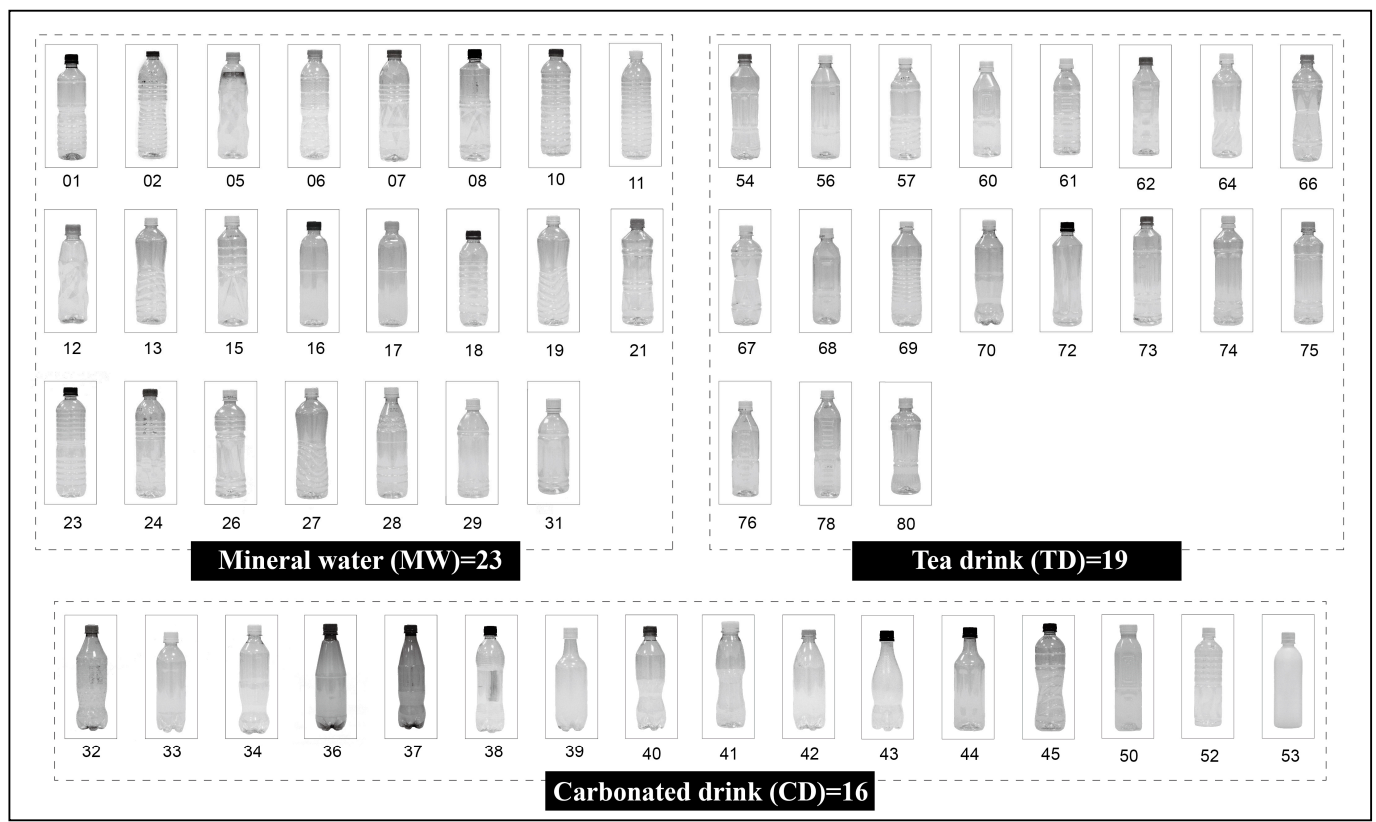

Figure 3. Fifty-eight evaluation samples of bottled beverage containers.

\subsection{Container Form Definition of Bottled Beverage Packaging}

To describe the form of a bottled beverage container, the morphological analysis method is introduced in this study. This method decomposes a system or product into its essential sub-concepts, each concept representing a dimension in a multi-dimensional matrix. Thus, new ideas are found by searching the matrix for new combinations of features [22]. This method has been widely applied in the packaging design field $[4,5,8,21]$. Having conducted an extensive review of 58 bottled beverage samples, a generic bottled beverage form is defined comprising four basic elements, namely the whole bottled form (X1), the neck treatment $(\mathrm{X} 2)$, the waist treatment $(\mathrm{X} 3)$, and the decoration/detail on the 
bottled form (X4). Each element has two form features, as shown in Figure 4. Based on a discussion between three designers, each of the 58 samples was then coded in accordance with the definition result of morphological analysis, as shown in Table 2.

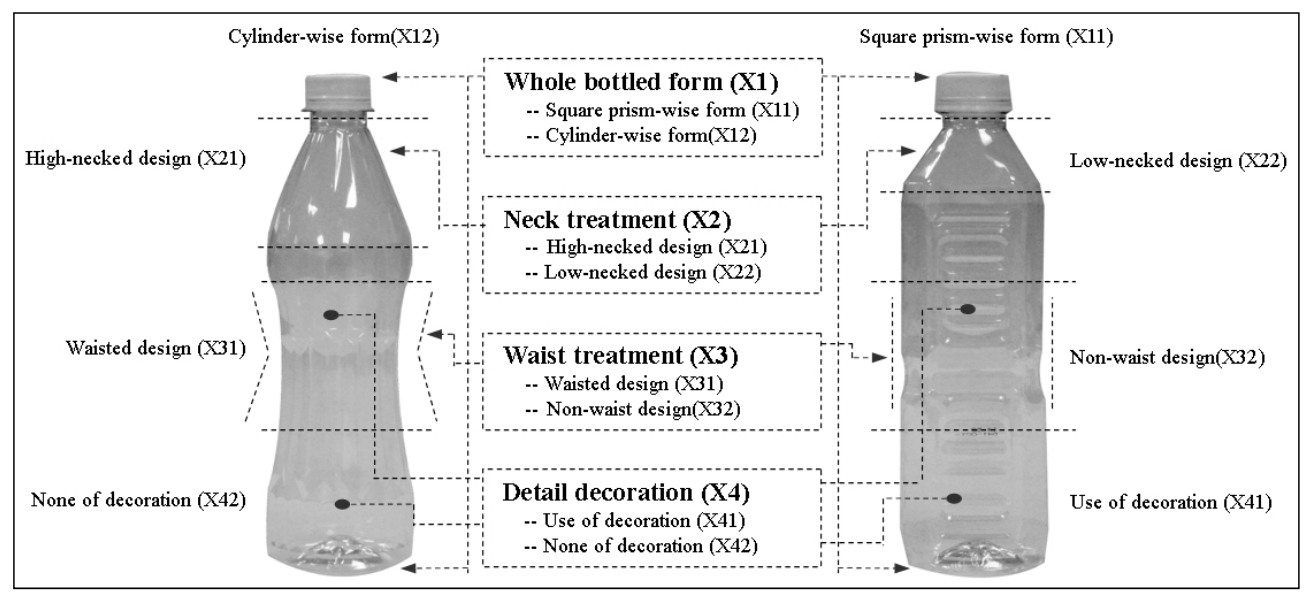

Figure 4. Pictorial illustration of morphological analysis results for bottled beverage containers.

Table 2. Coding of 58 bottled beverage samples (partial).

\begin{tabular}{ccccc}
\hline No. & X1 & X2 & X3 & X4 \\
\hline MW1 & X12 & X22 & X31 & X41 \\
MW2 & X12 & X21 & X31 & X41 \\
MW31 & $:$ & $:$ & $:$ & X42 \\
CD32 & X12 & X21 & X32 & X41 \\
CD33 & X12 & X21 & X32 & X42 \\
CD53 & $:$ & $:$ & $:$ & X42 \\
TD54 & X11 & X22 & X32 & X41 \\
TD56 & X11 & X22 & X32 & X41 \\
TD80 & X12 & X21 & $:$ & $:$ \\
\hline
\end{tabular}

\subsection{Descriptions of Consumers' Sentimental Responses (CSRs)}

Consumers commonly use adjectives to express their sentimental response to an object. Although many different adjectives are used when describing everyday product packaging, the adjectives applicable to bottled beverage packaging are limited. In this study, three designers, each with three years' experience in packaging design, and two white-collar individuals from non-design backgrounds were invited to participate in a discussion aimed at identifying suitable CSR descriptions (adjectives). These adjectives were elicited from the participants using the following four-step procedure:

- Step 1: The 58 beverage samples are reviewed, and the adjectives used by the individual participants to describe their sentimental responses to the beverage samples in three categories were recorded.

- Step 2: The Focus Group method was applied to select 39 suitable adjectives.

- Step 3: The Kawakida Jirou (K.J.) method was then applied to classify the 39 adjectives in accordance with their semantic similarities. As shown in Figure 5, three basic adjective groups are identified.

- Step 4: From each group, two descriptions are chosen to represent the overall characteristics of the group, i.e., "Tasteful \& Benevolent", "Delightful \& Young", and "Family \& Healthful". 


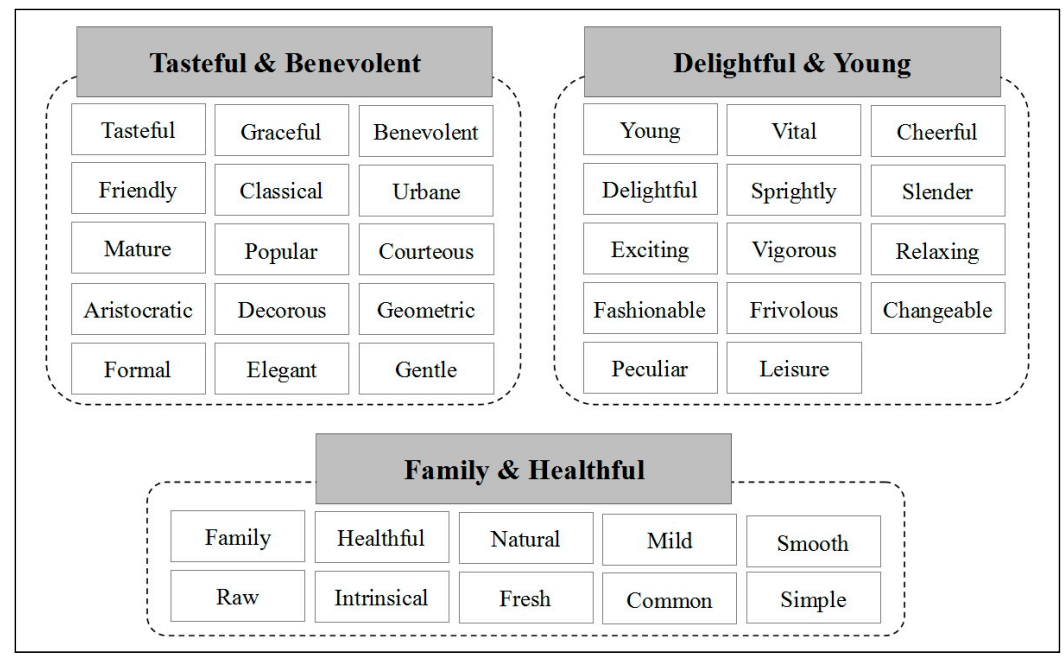

Figure 5. Selection and classification of consumers' sentimental response descriptions.

\section{Subjective Evaluation of Bottled Beverage Packaging Form}

The 58 samples of bottled beverage forms for three beverage categories (i.e., $\mathrm{MW}$ form $=23, \mathrm{CD}$ form $=16$ and TD form $=19$ ) presented in Figure 3 and the three CSR descriptions shown in Figure 5 were used to perform the correlation between the bottled beverage forms and their associated responses. The evaluation was performed using a total of 46 subjects, of whom 18 were designers with two years' experience in packaging or graphic design while 28 were individuals from non-design backgrounds.

In the evaluation process shown in Figure 6a, each sample is assessed in terms of the three CSR descriptions. Taking the first description, each subject divided the substantial samples into three groups, i.e., low $(\mathrm{L})$, medium $(\mathrm{M})$, and high $(\mathrm{H})$, in accordance with his or her intuitive response to a substantial sample of bottled beverage form. The subject then further divided each of the three groups into three sub-groups. In this way, the samples were divided into a total of nine groups. Each sample was then assigned a score from 1 to 9 (LL to HH) depending on the group to which it was assigned. Figure $6 \mathrm{~b}$ shows the execution of subjective evaluation for bottled beverage packaging. Having classified the samples of bottled beverage forms for three categories in terms of the first description, the two-stage classification process was repeated for each of the othertwo 2 descriptions. Finally, the evaluation results were used to analyze the correlation between the form of the bottled beverage and the associated CSRs utilizing the quantitative theory type I (QTT1) technique.

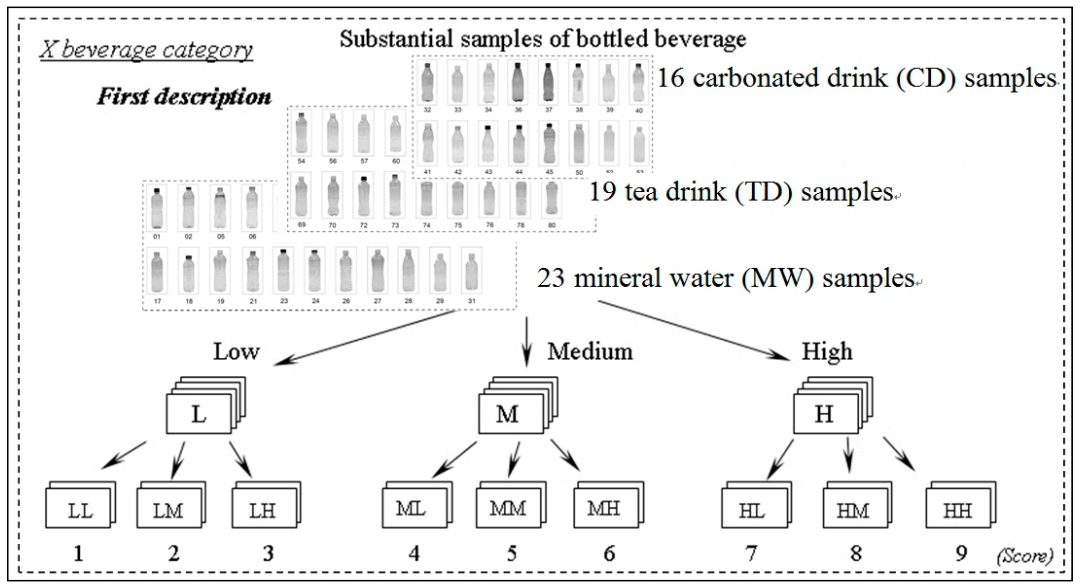

(a)

Figure 6. Cont. 


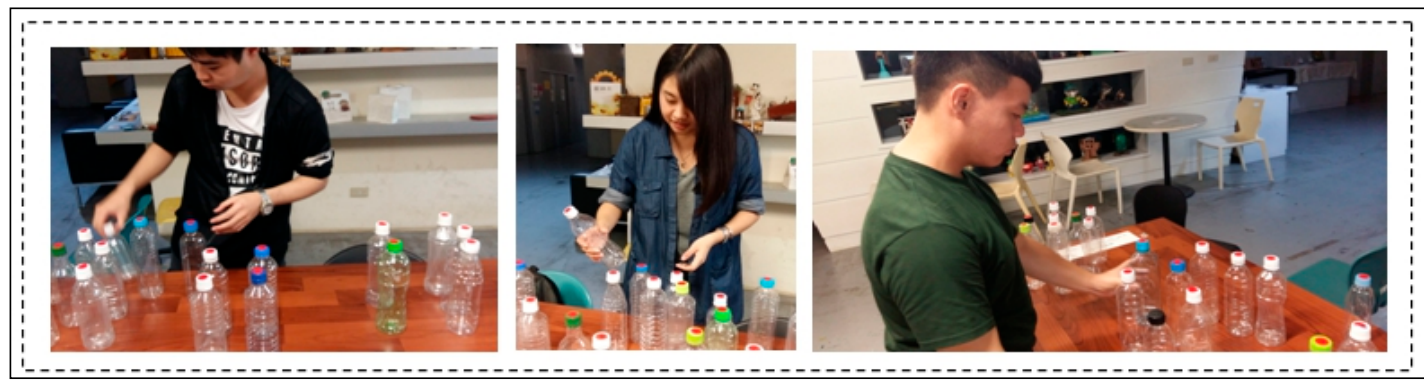

(b)

Figure 6. Subjective evaluation of bottled beverage packaging. (a) Procedural illustration of visual evaluation using SCEM (Sorting Card-based Evaluation Method), (b) Execution of visual evaluation.

\section{Analysis Results}

\subsection{Correlation between Beverage Container Form and CSR}

Based on the visual evaluation results of bottled beverage forms, QTT1 was used as a technique for modeling the correlation between the beverage container form and the CSR descriptions for each of three beverage categories. The independent variables correspond to the coding of bottled beverage samples, while the dependent variables correspond to the three CSR descriptions. Table 3 indicates the correlations between the beverage container form and the CSR descriptions for each of three beverage categories, and the QTT1 functional models in each of the three CSR descriptions for each of three beverage categories can be constructed using the data presented in the "category scores (CS)" columns of Table 3. On the whole, the $R^{2}$ values for each model range from 0.667 (Family \& Healthful) to 0.602 (Delightful \& Young) for the category of mineral water (MW), from 0.717 (Delightful \& Young) to 0.536 (Tasteful \& Benevolent) for the category of carbonated drinks (CD), and from 0.724 (Tasteful \& Benevolent) to 0.613 (Delightful \& Young) for tea drinks (TD). These results show that the overall fits of these QTT1 functional models are good.

Table 3. Analysis results of correlation model for three categories of bottled beverage containers.

\begin{tabular}{|c|c|c|c|c|c|c|c|}
\hline \multicolumn{8}{|l|}{ Mineral Water (MW) } \\
\hline \multirow{2}{*}{ Elements } & \multirow{2}{*}{ Features } & \multicolumn{2}{|c|}{ Family \& Healthful } & \multicolumn{2}{|c|}{ Delightful \& Young } & \multicolumn{2}{|c|}{ Tasteful \& Benevolent } \\
\hline & & PCC & CS & PCC & CS & PCC & CS \\
\hline $\begin{array}{l}\text { whole bottled form } \\
\text { (X1) }\end{array}$ & $\begin{array}{l}\mathrm{X} 11 \\
\mathrm{X} 12 \\
\end{array}$ & 0.316 & $\begin{array}{l}-0.252 \\
0.252\end{array}$ & 0.332 & $\begin{array}{c}-0.248 \\
0.248\end{array}$ & 0.307 & $\begin{array}{c}-0.241 \\
0.241\end{array}$ \\
\hline $\begin{array}{l}\text { neck treatment } \\
(\mathrm{X} 2)\end{array}$ & $\begin{array}{l}\mathrm{X} 21 \\
\mathrm{X} 22\end{array}$ & 0.192 & $\begin{array}{l}-0.175 \\
0.175\end{array}$ & 0.271 & $\begin{array}{l}0.205 \\
-0.205\end{array}$ & 0.096 & $\begin{array}{c}-0.103 \\
0.103\end{array}$ \\
\hline $\begin{array}{l}\text { waist treatment } \\
(\mathrm{X} 3)\end{array}$ & $\begin{array}{l}\text { X31 } \\
\text { X32 } \\
\end{array}$ & 0.385 & $\begin{array}{c}0.327 \\
-0.327 \\
\end{array}$ & 0.127 & $\begin{array}{c}0.141 \\
-0.141 \\
\end{array}$ & 0.214 & $\begin{array}{c}-0.187 \\
0.187 \\
\end{array}$ \\
\hline $\begin{array}{l}\text { detail decoration } \\
\text { on bottled form }(\mathrm{X} 4)\end{array}$ & $\begin{array}{l}X 41 \\
X 42 \\
\end{array}$ & 0.234 & $\begin{array}{c}0.162 \\
-0.162 \\
\end{array}$ & 0.133 & $\begin{array}{c}-0.078 \\
0.078\end{array}$ & 0.172 & $\begin{array}{c}0.124 \\
-0.124\end{array}$ \\
\hline $\begin{array}{c}\text { Constant } \\
R \\
R^{2}\end{array}$ & & & & & & & \\
\hline \multicolumn{8}{|c|}{ Carbonated Drinks (CD) } \\
\hline \multirow{2}{*}{ Elements } & \multirow{2}{*}{ Features } & \multicolumn{2}{|c|}{ Family \& Healthful } & \multicolumn{2}{|c|}{ Delightful \& Young } & \multicolumn{2}{|c|}{ Tasteful \& Benevolent } \\
\hline & & PCC & CS & PCC & CS & PCC & CS \\
\hline $\begin{array}{l}\text { whole bottled form } \\
\text { (X1) }\end{array}$ & $\begin{array}{l}\mathrm{X} 11 \\
\mathrm{X} 12\end{array}$ & 0.134 & $\begin{array}{l}-0.106 \\
0.106\end{array}$ & 0.321 & $\begin{array}{c}-0.328 \\
0.328\end{array}$ & 0.207 & $\begin{array}{c}0.225 \\
-0.225\end{array}$ \\
\hline $\begin{array}{l}\text { neck treatment } \\
(\mathrm{X} 2)\end{array}$ & $\begin{array}{l}\mathrm{X} 21 \\
\mathrm{X} 22\end{array}$ & 0.435 & $\begin{array}{l}0.427 \\
-0.427\end{array}$ & 0.481 & $\begin{array}{l}0.607 \\
-0.607\end{array}$ & 0.279 & $\begin{array}{c}0.318 \\
-0.318\end{array}$ \\
\hline
\end{tabular}


Table 3. Cont.

\begin{tabular}{|c|c|c|c|c|c|c|c|}
\hline \multicolumn{8}{|l|}{ Mineral Water (MW) } \\
\hline $\begin{array}{l}\text { waist treatment } \\
(\mathrm{X} 3)\end{array}$ & $\begin{array}{l}\text { X31 } \\
\text { X32 }\end{array}$ & 0.296 & $\begin{array}{c}0.311 \\
-0.311\end{array}$ & 0.217 & $\begin{array}{c}-0.213 \\
0.213\end{array}$ & 0.262 & $\begin{array}{c}0.286 \\
-0.286\end{array}$ \\
\hline $\begin{array}{l}\text { detail decoration } \\
\text { on bottled form }(\mathrm{X} 4)\end{array}$ & $\begin{array}{l}X 41 \\
X 42\end{array}$ & 0.195 & $\begin{array}{c}0.242 \\
-0.242\end{array}$ & 0.301 & $\begin{array}{c}-0.297 \\
0.297\end{array}$ & 0.237 & $\begin{array}{c}0.542 \\
-0.952\end{array}$ \\
\hline $\begin{array}{c}\text { Constant } \\
R \\
R^{2}\end{array}$ & & & & & & & \\
\hline \multicolumn{8}{|l|}{ Tea Drinks (TD) } \\
\hline \multirow{2}{*}{ Elements } & \multirow{2}{*}{ Features } & \multicolumn{2}{|c|}{ Family \& Healthful } & \multicolumn{2}{|c|}{ Delightful \& Young } & \multicolumn{2}{|c|}{ Tasteful \& Benevolent } \\
\hline & & PCC & CS & PCC & CS & PCC & CS \\
\hline $\begin{array}{l}\text { whole bottled form } \\
\text { (X1) }\end{array}$ & $\begin{array}{l}\mathrm{X} 11 \\
\mathrm{X} 12\end{array}$ & 0.168 & $\begin{array}{c}-0.174 \\
0.174\end{array}$ & 0.272 & $\begin{array}{c}0.268 \\
-0.268\end{array}$ & 0.746 & $\begin{array}{c}0.825 \\
-0.825\end{array}$ \\
\hline $\begin{array}{l}\text { neck treatment } \\
(\mathrm{X} 2)\end{array}$ & $\begin{array}{l}X 21 \\
X 22\end{array}$ & 0.139 & $\begin{array}{c}0.143 \\
-0.143\end{array}$ & 0.115 & $\begin{array}{c}-0.107 \\
0.107\end{array}$ & 0.169 & $\begin{array}{c}-0.174 \\
0.174\end{array}$ \\
\hline $\begin{array}{l}\text { waist treatment } \\
(\mathrm{X} 3)\end{array}$ & $\begin{array}{l}\text { X31 } \\
\text { X32 } \\
\end{array}$ & 0.312 & $\begin{array}{c}0.338 \\
-0.338\end{array}$ & 0.296 & $\begin{array}{c}0.302 \\
-0.302 \\
\end{array}$ & 0.293 & $\begin{array}{c}0.304 \\
-0.304\end{array}$ \\
\hline $\begin{array}{l}\text { detail decoration } \\
\text { on bottled form (X4) }\end{array}$ & $\begin{array}{l}X 41 \\
X 42\end{array}$ & 0.385 & $\begin{array}{c}0.376 \\
-0.376\end{array}$ & 0.281 & $\begin{array}{c}-0.286 \\
0.286\end{array}$ & 0.347 & $\begin{array}{c}0.443 \\
-0.443\end{array}$ \\
\hline $\begin{array}{c}\text { Constant } \\
R \\
R^{2}\end{array}$ & & & & & & & \\
\hline
\end{tabular}

\subsection{Explanation of Analysis Results for Three Beverage Categories}

The partial correlation coefficient (PCC) values in Table 3 indicate the influence of beverage container form elements on CSR descriptions. If the value is bigger, it will have more influence on CSR descriptions. Furthermore, the absolute value of CS determines the intensity of the container feature, while its sign determines the nature of the container feature (i.e., a positive or negative effect on consumers' response). In other words, a positive value of the CS indicates that adjusting the corresponding feature in the proper way reinforces the CSR descriptions. For instance, for mineral water containers, variable X31 is the "waisted design" for the "waist treatment (X3)". The CS column of Table 3 reveals that the CS value of this variable is positive (0.327), which indicates that a refinement in the waisted detail design causes the container form to be perceived as more "Family \& Healthful". Similarly, variable X12 is the "cylinder-wise form" for the "whole bottled form (X1)". Its CS value (0.252) indicates that a columnar trait on the bottled form means the mineral water container is perceived as more "Family \& Healthful". The effects of PCC and CS on the remaining CSR descriptions of three beverage categories were interpreted via the signs of the corresponding values in a manner analogous to that described above for the "Family \& Healthful" description domain of the mineral water container.

\subsection{Principal Form Elements Influencing Consumers' Responses}

In order to explore the principal form elements influencing CSR to bottled beverage container forms, the relative influence of each PCC to a particular CSR description was evaluated by normalizing the $P C C$ values to a value within the interval $[0,1]$ in accordance with the following formulation:

$$
N P C C=\frac{\left|P C C_{i}\right|}{\sum_{i=1}^{n}\left|P C C_{i}\right|}
$$

where NPCC denotes the normalized PCC value, PCC $i$ is the PCC value of the $i$-th form element within the specified CSR description, and $n$ is the total number of original form elements. Specifically, 
the original elements were sorted in descending order based on their NPCC values, and the NPCC values were then added sequentially from the largest to the smallest until the cumulative total exceeded a predetermined threshold value. The corresponding original elements were then nominated as principal form elements influencing CSR. Note that the threshold value is assigned a value of 0.70 , indicating that the corresponding principal form elements accounted for $70 \%$ of the correlation between all the original form elements and the CSR description. As in the procedure applied to identify the principal form elements, the form elements were sorted in descending order based on their PCC values and these values were then added sequentially from the largest to the smallest until the cumulative total exceeded $70 \%$. The corresponding original form elements were then nominated as principal form elements influencing CSR.

Table 4 summarizes the principal form elements of bottled beverage containers for each of the three CSR descriptions in terms of three beverage categories. On the whole, it can be seen that the form elements are imparted by the whole bottled form (X1), the waisted treatment $(X 3)$, and the detail/decoration on the bottle form (X4) for MW containers, and by the neck treatment (X2), the waist treatment (X3), and the detail/decoration on the bottle form (X4) for CD containers. Similarly, the principal form elements associated with the three CSR descriptions include the whole bottled form (X1), the waisted treatment (X3), and the detail/decoration on the bottle form (X4) for TD containers. Consequently, if a designer wishes to create a bottled beverage container form with the "Family \& Healthful", "Delightful \& Young", or "Tasteful \& Benevolent" image, he or she can focus attention on these particular form elements and their corresponding features. Overall, the analysis results provide commercial packaging designers or manufacturers with useful cues to understand the effects of the main elements and features of the form design of bottled beverage packaging when developing bottled beverage containers.

Table 4. Principal form elements in each CSR description for three beverage categories.

\begin{tabular}{|c|c|c|c|c|c|c|c|}
\hline \multirow{2}{*}{\multicolumn{2}{|c|}{$\begin{array}{l}\text { CSR Description } \\
\text { Form Elements }\end{array}$}} & \multicolumn{2}{|c|}{ Family \& Healthful } & \multicolumn{2}{|c|}{ Delightful \& Young } & \multicolumn{2}{|c|}{ Tasteful \& Benevolent } \\
\hline & & PCC & NPCC & PCC & NPCC & PCC & NPCC \\
\hline \multirow{3}{*}{$\begin{array}{l}\text { whole bottled form } \\
\text { (X1) }\end{array}$} & MW & 0.316 & $* 28.0 \%$ & 0.332 & $* 38.5 \%$ & 0.307 & $* 38.9 \%$ \\
\hline & CD & 0.134 & $12.6 \%$ & 0.321 & $24.3 \%$ & 0.207 & $21.0 \%$ \\
\hline & $\mathrm{TD}$ & 0.168 & ${ }^{*} 16.7 \%$ & 0.272 & $* 28.2 \%$ & 0.746 & $* 48.0 \%$ \\
\hline \multirow{3}{*}{$\begin{array}{l}\text { neck treatment } \\
(\mathrm{X} 2)\end{array}$} & MW & 0.192 & $17.0 \%$ & 0.271 & $* 31.4 \%$ & 0.096 & $12.2 \%$ \\
\hline & CD & 0.435 & $* 41.0 \%$ & 0.481 & $* 36.4 \%$ & 0.279 & $* 28.3 \%$ \\
\hline & $\mathrm{TD}$ & 0.139 & $13.8 \%$ & 0.115 & $11.9 \%$ & 0.169 & $10.9 \%$ \\
\hline \multirow{3}{*}{$\begin{array}{l}\text { waist treatment } \\
\text { (X3) }\end{array}$} & MW & 0.385 & $* 34.2 \%$ & 0.127 & $14.7 \%$ & 0.214 & $* 27.1 \%$ \\
\hline & CD & 0.296 & $* 27.9 \%$ & 0.217 & $16.4 \%$ & 0.262 & $* 26.6 \%$ \\
\hline & $\mathrm{TD}$ & 0.312 & $* 31.1 \%$ & 0.296 & $* 30.7 \%$ & 0.293 & $18.8 \%$ \\
\hline \multirow{3}{*}{$\begin{array}{l}\text { detail decoration on } \\
\text { bottled form }(X 4)\end{array}$} & MW & 0.234 & $* 20.8 \%$ & 0.133 & ${ }^{*} 15.4 \%$ & 0.172 & $* 21.8 \%$ \\
\hline & CD & 0.195 & ${ }^{*} 18.4 \%$ & 0.301 & ${ }^{*} 22.8 \%$ & 0.237 & $* 24.1 \%$ \\
\hline & $\mathrm{TD}$ & 0.385 & $* 38.3 \%$ & 0.281 & ${ }^{*} 29.1 \%$ & 0.347 & $* 22.3 \%$ \\
\hline
\end{tabular}

(1) Asterisk in NPCC column indicates the principal form element in terms of the corresponding beverage categories.

(2) "MW", "CD", and "TD" indicate "mineral water", "carbonated drinks", and "tea drinks", respectively.

\section{Conclusions}

This study has explored the form elements and the corresponding features of bottled beverage containers. A series of visual evaluations with bottled beverage container forms as examples has been conducted to illustrate the implementation procedure. The principal elements of bottled container forms for three beverage categories have been identified such that the process of developing a new container design for meeting consumers' sentimental expectations can be enhanced. The methodology and procedure not only provides the designer with the ability to inspect the form elements and the corresponding features for bottled container forms, but also allows him or her to develop a new 
container form that is likely to satisfy CSR descriptions in terms of three beverage categories in this study. However, consumers' responses to a bottled beverage container form are both complicated and changeable over time. Different consumers are almost certain to experience a different psychological or sentimental response when presented with the same container form. As a consequence, there is no certainty that the design result obtained using the proposed procedure will satisfy all customers, either now or in the future. In addition, these relationship models based on the QTT1 technique provide designers with the means to design a bottled beverage form to meet a single CSR description, and cannot consider a suitable alternative based on multiple CSR descriptions. In future studies, it would be worthwhile considering the integrated use of other multi-objective analysis techniques so that multiple consideration-based models (i.e., based on multiple CSR descriptions) can be developed.

Author Contributions: The authors contributed equally to the collection of bottled beverage container samples, to the design and implementation of the research, to the analysis of the results and to the writing of the manuscript.

Acknowledgments: The authors gratefully acknowledge the support provided by the Ministry of Science and Technology of Taiwan under grant No. MOST 106-2410-H-218-011.

Conflicts of Interest: The authors declare no conflict of interest.

\section{References}

1. Becker, L.; van Rompay, T.J.L.; Schifferstein, H.N.J.; Galetzka, M. Tough package, strong taste: The influence of packaging design on taste impressions and product evaluations. Food Qual. Preference 2011, 22, 17-23. [CrossRef]

2. Luo, S.J.; Fu, Y.T.; Korvenma, P. A preliminary study of perceptual matching for the evaluation of beverage bottle design. Int. J. Ind. Ergon. 2012, 42, 219-232. [CrossRef]

3. Giese, J.L.; Malkewitz, K.; Orth, U.R.; Henderson, P.W. Advancing the aesthetic middle principle: Trade-offs in design attractiveness and strength. J. Bus. Res. 2014, 67, 1154-1161. [CrossRef]

4. Ares, G.; Deliza, R. Studying the influence of package shape and colour on consumer expectations of milk desserts using word association and conjoint analysis. Food Qual. Preference 2010, 21, 930-937. [CrossRef]

5. Henson, B.; Barnes, C.; Livesey, R.; Childs, T.; Ewart, K. Affective consumer requirements: A case study of moisturizer packaging. Concurr. Eng. Res. Appl. 2006, 14, 187-196. [CrossRef]

6. Fernqvist, F.; Olsson, A.; Spendrup, S. What's in it for me? Food packaging and consumer responses, a focus group study. Br. Food J. 2015, 117, 1122-1135. [CrossRef]

7. Nagamachi, M. Kansei engineering as a powerful consumer-oriented technology for product development. Appl. Ergon. 2002, 33, 289-294. [CrossRef]

8. Chen, H.Y. Development of perfume bottle visual design model using fuzzy analytic herarchy process. Art Des. Rev. 2017, 5, 13-25.

9. Chang, H.C.; Chen, H.Y. Exploration of action figure appeal using evaluation grid method and quantification theory type I. Eurasia J. Math. Sci. Technol. Educ. 2017, 13, 1445-1459. [CrossRef]

10. Tung, T.C.; Chen, H.Y. Integrating conjoint analysis with TOPSIS algorithm to the visual effect of icon design critical to users' image perceptions. Eurasia J. Math. Sci. Technol. Educ. 2017, 13, 1025-10403. [CrossRef]

11. Chen, H.Y.; Chang, H.C. Consumers' perception-oriented product form design using multiple regression analysis and back-propagation neural network. Artif. Intell. Eng. Des. Anal. Manuf. 2016, 30, 64-77. [CrossRef]

12. Vazquez, D.; Bruce, M.; Studd, R. A case study exploring the packaging design management process within a UK food retailer. Br. Food J. 2003, 105, 20-31. [CrossRef]

13. Silayoi, P.; Speece, M. The importance of packaging attributes: A conjoint analysis approach. Eur. J. Mark. 2007, 41, 1495-1517. [CrossRef]

14. Siripuk, R.; Nopadon, S. Package design determining young purchasers buying decision: A cosmetic packaging case study on gender distinction. Procedia Soc. Behav. Sci. 2012, 38, 373-379.

15. Carneiro, J.D.S.; Minim, V.P.R.; Deliza, R.; Silva, C.H.O.; Carneiro, J.C.S.; Leão, F.P. Labelling effects on consumer intention to purchase for soybean oil. Food Qual. Preference 2005, 16, 275-282. [CrossRef]

16. Wells, L.E.; Farley, H.; Armstrong, G.A. The importance of packaging design for own-label food brands. Int. J. Retail Distrib. Manag. 2007, 35, 677-690. [CrossRef] 
17. Young, S. New and improved indeed: Documenting the business value of packaging innovation. Quirk's Mark. Res. Rev. 2008, 22, 46-50.

18. Löfgren, M.; Witell, L.; Gustafsson, A. Customer satisfaction in the first and second moments of truth. J. Prod. Brand Manag. 2008, 17, 463-474. [CrossRef]

19. Metcalf, L.; Hess, J.S.; Danes, J.E.; Singh, J. A mixed-methods approach for designing market-driven packaging. Qual. Mark. Res. Int. J. 2012, 15, 268-289. [CrossRef]

20. Tunyarut, J.; Prisana, S. Trade-off analysis of packaging attributes for foods and drinks. Br. Food J. 2015, 117, 139-156.

21. Lin, Y.-C.; Wei, C.-C. The QTTI-based TOPSIS decision support model to fragrance form design. In Proceedings of the 2014 International Symposium on Computer, Consumer and Control, Taichung, Taiwan, 10-12 June 2014; pp. 1291-1294.

22. Zwicky, F. Discovery, Invention, Research through the Morphological Analysis; The Macmillan Company: Basingstoke, UK, 1969.

23. Prokopska, A. Application of morphological analysis methodology in architectural design. Acta Polytech. 2001, 41, 46-54.

24. Paul, C. Morphological computation: A basis for the analysis of morphology and control requirements. Robot. Autom. Syst. 2006, 54, 619-630. [CrossRef]

25. Lai, H.H.; Lin, Y.C.; Yeh, C.H. Form design of product image using grey relational analysis and neural network models. Comput. Oper. Res. 2005, 32, 2689-2711. [CrossRef]

26. Chang, H.C.; Lai, H.H.; Chang, Y.M. A measurement scale for evaluating the attractiveness of a passenger car form aimed at young consumers. Int. J. Ind. Ergon. 2007, 37, 21-30. [CrossRef]

27. Likert, R. A technique for the measurement of attitudes. Arch. Psychol. 1932, 140, 55.

28. Osgood, C.E.; Suci, G.J.; Tannenbaum, P.H. The Measurement of Meaning; University of Illinois Press: Champaign, IL, USA, 1957.

29. Gofman, A.; Moskowitz, H.R.; Mets, T. Accelerating structured consumer-driven package design. J. Consum. Mark. 2010, 27, 157-168. [CrossRef]

30. Huang, Y.; Chen, C.H.; Khoo, L.P. Products classification in emotional design using a basic-emotion based semantic differential method. Int. J. Ind. Ergon. 2012, 42, 569-580. [CrossRef]

31. McDonagh, D.; Denton, H. Exploring the degree to which individual students share a common perception of specific mood boards: Observations relating to teaching, learning and team-based design. Des. Stud. 2005, 26, 35-53. [CrossRef]

32. Chen, H.Y.; Chang, Y.M.; Chang, H.C. A numerical definition-based systematic design approach for coupling consumers' image perception with product form. J. Eng. Des. Technol. 2016, 14, 134-159. [CrossRef] 